\title{
Lung Sequestration in an Octogenarian Male
}

\author{
Hugo Bonatti, ${ }^{1}$ Eva Smorzanek, ${ }^{2}$ and Frank Brennan ${ }^{2}$
}

1. Department of Surgery, University of Maryland, Memorial Hospital at Easton, Easton, MD, US; 2. Department of Radiology, University of Maryland, Memorial Hospital at Easton, Easton, MD, US

DOl: https://doi.org/10.17925/USRPD.2017.12.02.37

$\mathrm{L}$

ung sequestration is a congenital disorder in which the lung parenchyma is not attached to the bronchial system, with blood supply originating from the aorta or various peripheral arteries. It may cause chronic pulmonary infection or bleeding and may require surgical resection. An 80-year-old male was incidentally found to have a paravertebral right thoracic mass. Computed tomography scan with contrast suggested a feeding vessel from the supraceliac aorta and suspicion of a lung sequestration was confirmed on selective angiography. He developed chronic cough, but this was managed symptomatically and no specific treatment, such as surgical resection, was necessary. Lung sequestration in the elderly is a rare condition but should be considered in a patient presenting with stable lung lesions, especially if a feeding artery from the aorta can be identified.

\section{Keywords}

Lung sequestration, chronic cough, angiography

Disclosure: Hugo Bonatti, Eva Smorzanek, and Frank Brennan have nothing to declare in relation to this article.

Compliance with Ethics: Written informed consent was not obtained from the patient case included in this report; no identifying information or images have been used.

Authorship: All named authors meet the International Committee of Medical Journal Editors (ICMJE) criteria for authorship of this manuscript, take responsibility for the integrity of the work as a whole, and have given final approval to the version to be published.

open Access: This article is published under the Creative Commons Attribution Noncommercial License, which permits any noncommercial use, distribution, adaptation, and reproduction provided the original author(s) and source are given appropriate credit.

Received: July 3, 2017

Accepted: September 17, 2017

Citation: US Respiratory \& Pulmonary Diseases, 2017;2(1):37-9

Corresponding Author: Hugo Bonatti, University of Maryland, Community Medical Group Surgical Care, 500 Cadmus Lane, Suite 280, Easton,

MD 21601, US. E: hugo.bonatti@dr.com

Support: No funding was received in the publication of this article.
Lung, pulmonary, or broncholpulmonary sequestration is a congenital disorder in which tissue that develops into lung parenchyma is not attached to the bronchial system. ${ }^{1}$ Blood supply originates from the aorta or various peripheral arteries. ${ }^{1,2}$ It is also referred to as cystic lung disease. The intralobar type accounts for approximately $75 \%$ of cases; extralobar pulmonary sequestration accounts for $25 \%$ of cases, is located extrapulmonarily and forms its own visceral pleura. ${ }^{3,4}$ The majority of these lesions are diagnosed in children; intrauterine diagnosis using prenatal ultrasound and magnet resonance imaging are available. ${ }^{5}$ Intrauterine interventional procedures are an exciting new therapeutic option. ${ }^{6}$ Such lesions may completely regress during pregnancy. If they persist and are symptomatic, surgical removal is indicated. In adults, incidental detection of such lesions on computed tomography (CT) scan is common and patients may not have any symptoms. If symptomatic, pulmonary sequestration presents with chronic pulmonary infections, chronic dry cough, or hemoptysis. ${ }^{7.8}$ Treatment in adults is controversial and depends mainly on symptoms, and may include percutaneous embolization of the feeding artery, thoracoscopic, or open surgery. ${ }^{9-12}$ However, in many cases, no treatment is required, ${ }^{13}$ especially in patients of advanced age. ${ }^{14}$ Diagnosis of this disorder beyond the age of 60 years is extremely rare. ${ }^{13,14}$

\section{Case report}

An 80-year-old male underwent a cardiac CT scan showing a $1.9 \times 2.3 \mathrm{~cm}$ lesion in the right posterior mediastinum. The patient had no cough, chest pain, or other symptoms. A positron emission tomography (PET) scan was subsequently performed and the lesion was negative for radionuclide uptake. Magnetic resonance imaging (MRI) of the thoracic spine two years later showed again the stable mass (Figure $1 A$ and $1 B$ ). He remained symptom-free for three years, after which he developed chronic cough. A contrasted CT scan was done and the mass at the lung base had not shown any growth (Figure $2 A$ and $2 B$ ). The patient was referred to surgery and it was decided that a percutaneous CT-guided biopsy should be performed. On further review of the CT scan, however, a feeding artery from the intra-abdominal aorta was seen (Figure $3 A$ and $3 B$ ) and it was then suspected that the lesion could be a pulmonary sequestration. An angiogram was performed and, indeed, the feeding blood vessel from the supraceliac aorta could be visualized, confirming the diagnosis (Figure 4). The lesion drained into the pulmonary venous system. No biopsy and no additional treatments were done and the patient was assured that this was a benign lesion and that his cough should be symptomatically treated. Initially, he did well, however, a year later he developed pneumonia, which was successfully treated with antibiotics. He is alive and well seven years after initial detection of the lesion. 

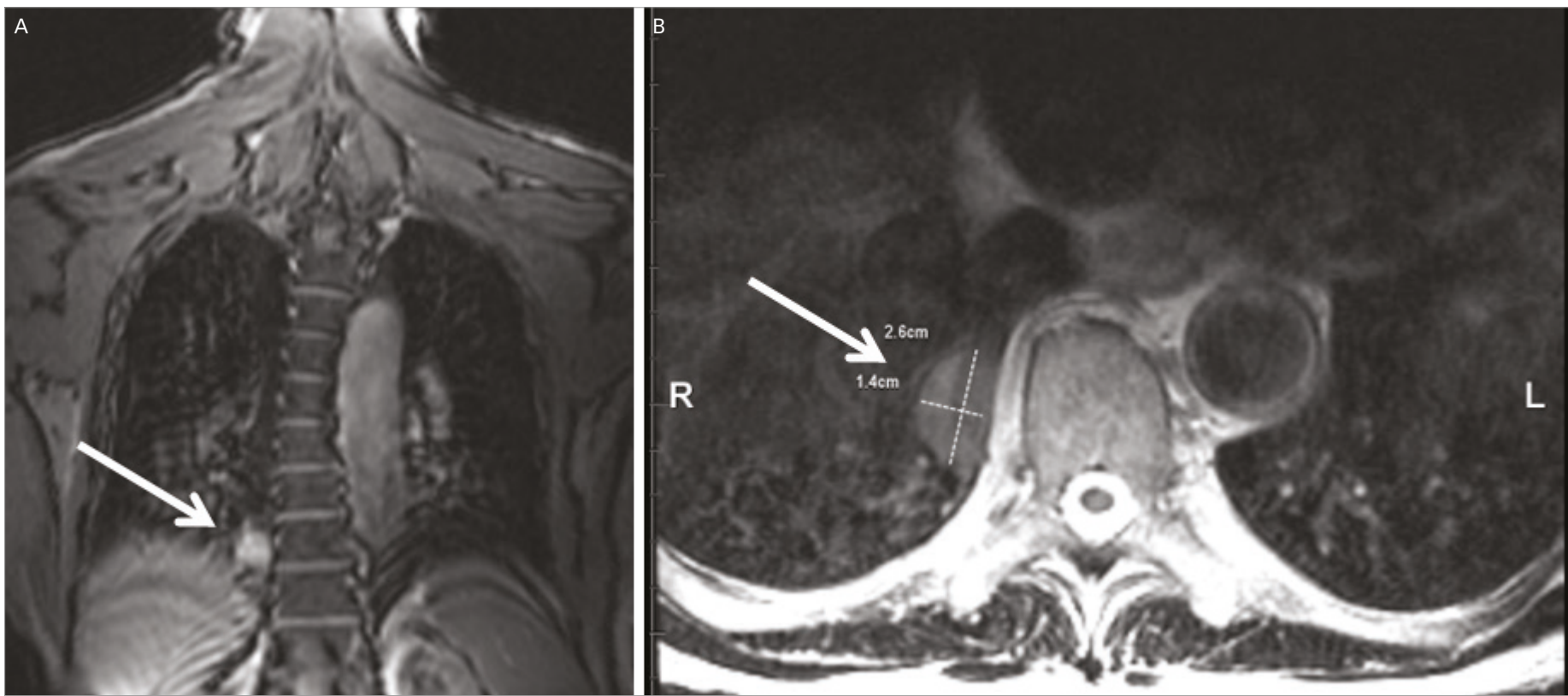

Figure 2: Computed tomography scan—right paravertebral mass (arrows)

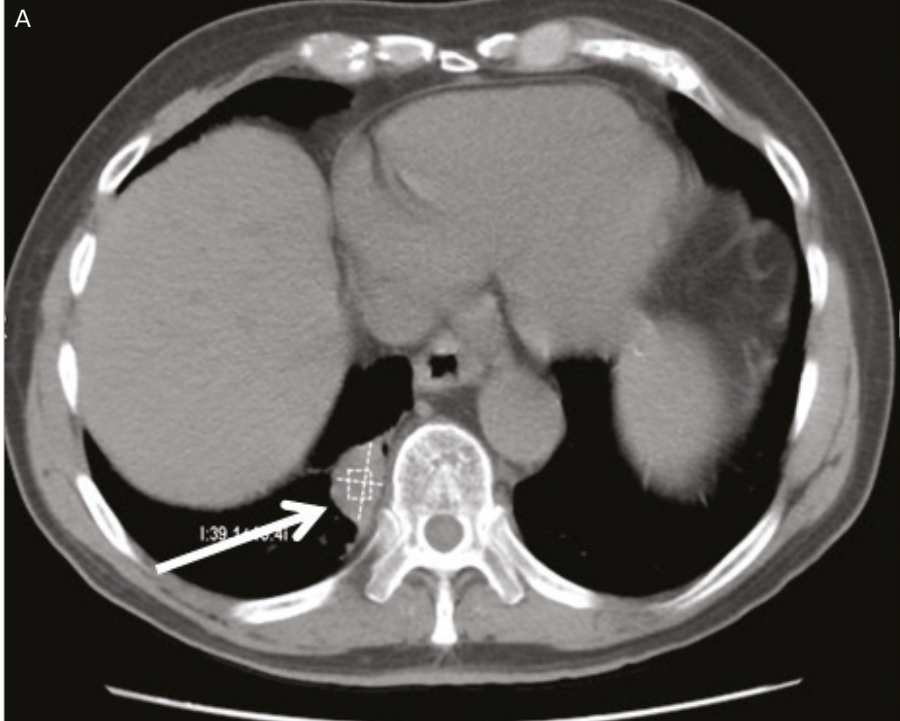

\section{Discussion}

We report on an octogenarian male who presented with chronic cough and was found to have a pulmonary nodule. Differential diagnoses of such lesions in the elderly include benign and malignant tumors, infections, and malformations such as pulmonary sequestration. ${ }^{3}$ Primary lung cancer and metastases of various cancers and a variety of benign lung lesions such as neurogenic tumors need to be considered; PET/CT scan frequently helps in establishing diagnosis. ${ }^{15}$ It should be noted that this type of malformation is diagnosed extremely rarely in individuals older than 60 years. ${ }^{13,14}$ Montjoy et al. reported three adult patients with pulmonary sequestration; they were aged 57 to 62 years, ${ }^{8}$ and the oldest patient in the Gompelmann series from Germany was 59 years old. ${ }^{7}$ In a large series from Florida including 29 patients with pulmonary sequestration published by Tashtoush et al.,

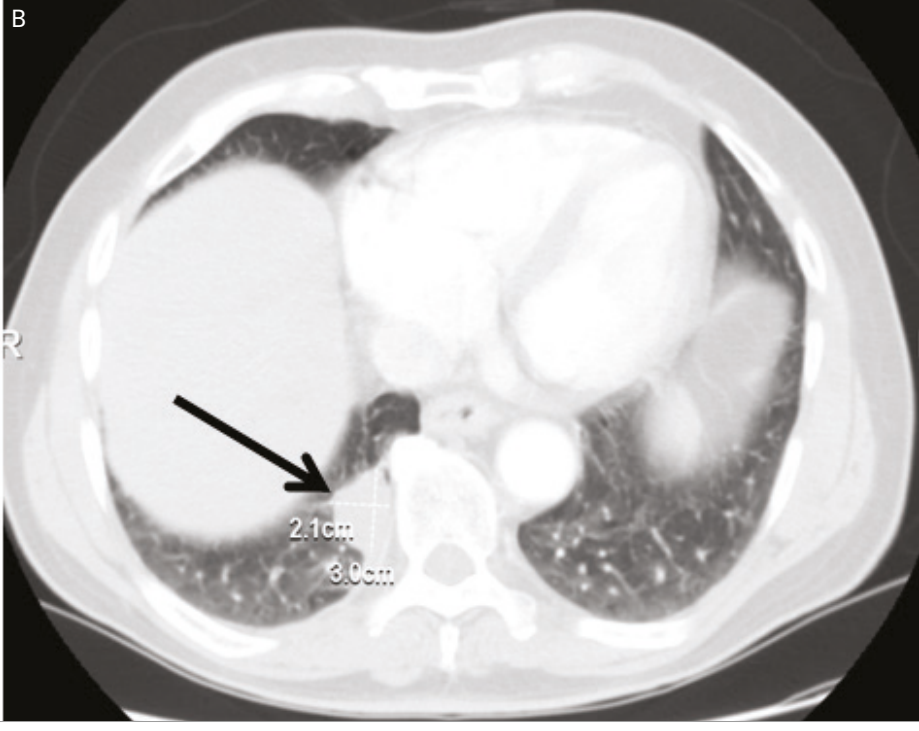

almost two thirds of individuals were adults, with the oldest being 70 years old. ${ }^{11}$ The authors emphasized that many had a delay in diagnosis, as other more common pulmonary conditions were initially considered. Almost all patients in these series underwent surgical treatment. ${ }^{7.8}$ Diagnosis of pulmonary sequestration in adults may be difficult both on chest X-ray and uncontrasted CT scan. During the arterial phase of the contrasted CT scan, the feeding vessel, which commonly originates from the thoracic or supraceliac abdominal aorta may become visible, allowing accurate diagnosis. ${ }^{2,8,11}$ In our case we opted for aortic angiography. Huang et al. reported on the use of Doppler sonography in the diagnosis of pulmonary sequestration in another octogenarian patient, however, they subsequently confirmed findings on CT angiography. ${ }^{13}$ This patient also did not require intervention as he was not very symptomatic. 
Figure 3: Computed tomography scan-feeding artery to the lung sequestration arising from supraceliac aorta (arrows)
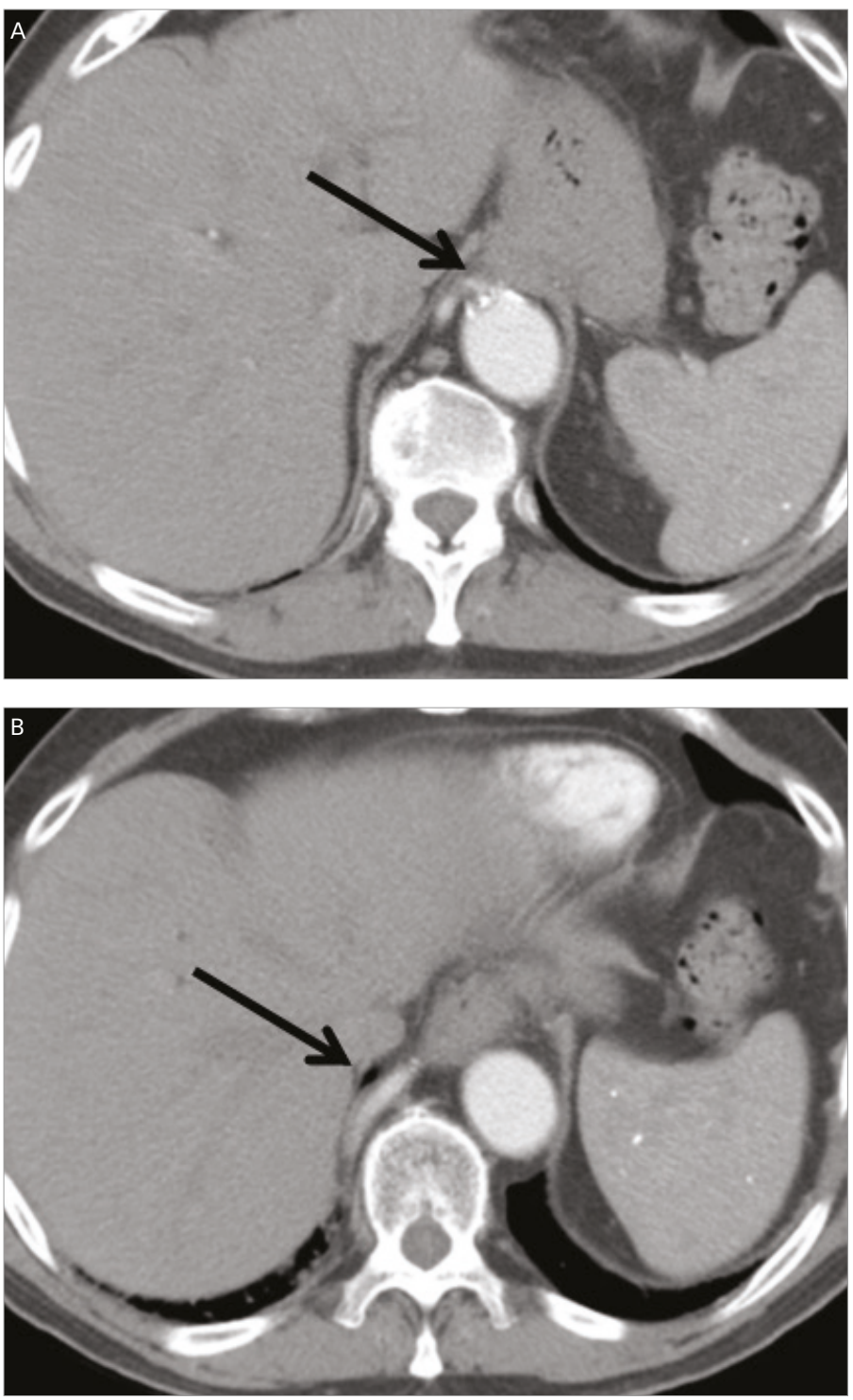

Figure 4: Angiography—selective arteriogram of the feeding artery to the lung sequestration

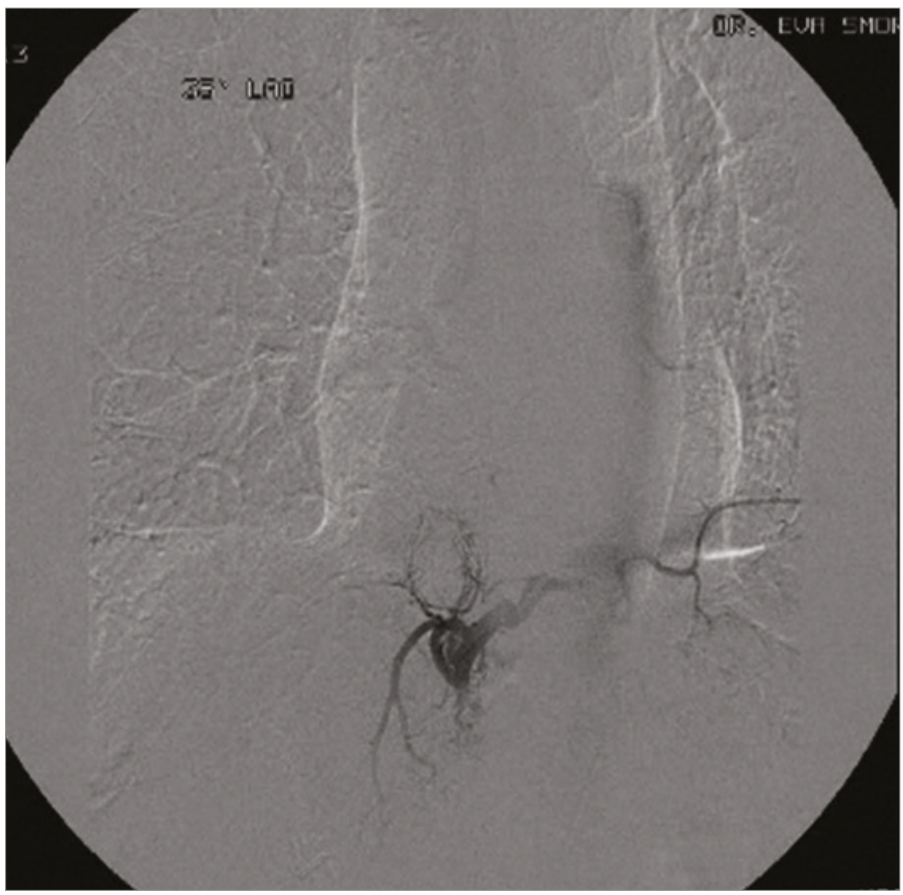

Our patient was not very symptomatic and did not desire any interventions given his advanced age. Many patients with smaller lesions do not require special treatment. If the lesion is symptomatic, causing recurrent infections, percutaneous embolization through the feeding vessel is an option. Embolization has also been performed in case of massive hemoptysis associated with pulmonary sequestration, as bleeding from these lesions may be fatal. $9,10,16$

To summarize, contrast-enhanced chest CT scan suggested pulmonary sequestration in this elderly gentleman and diagnosis was confirmed by identifying the feeding vessel with angiography. As the lesion was benign and the patient had only minimal symptoms, no additional interventions were made. $\square$
1. Bailey PV, Tracy T Jr, Connors RH, et al., Congenital bronchopulmonary malformations. Diagnostic and therapeutic considerations, J Thorac Cardiovasc Surg, 1990;99:597-602; discussion-3.

2. Zylak CJ, Eyler WR, Spizarny DL, Stone $\mathrm{CH}$, Developmental lung anomalies in the adult: radiologic-pathologic correlation, Radiographics, 2002;22 Spec No:S25-43.

3. Fievet $L$, Natale $C, D^{\prime} J$ Journo $X B$, et al., Congenital pulmonary airway malformation and sequestration: two standpoints for a single condition, J Minim Access Surg, 2015;11:129-33.

4. Wei Y, Li F, Pulmonary sequestration: a retrospective analysis of 2625 cases in China, Eur J Cardiothorac Surg, 2011;40:e39-42.

5. Hung JH, Shen $\mathrm{SH}$, Guo WY, et al., Prenatal diagnosis of pulmonary sequestration by ultrasound and magnetic resonance imaging J Chin Med ASSOC, 2008;71:53-7.

6. Ruano R, de A Pimenta EJ, Marques da Silva M, et al.,
Percutaneous intrauterine laser ablation of the abnormal vessel in pulmonary sequestration with hydrops at 29 weeks' gestation, J Ultrasound Med, 2007;26:1235-41.

7. Gompelmann $\mathrm{D}$, Eberhardt R, Heussel $\mathrm{CP}$, et al., Lung sequestration: a rare cause for pulmonary symptoms in adulthood, Respiration, 2011:82:445-50.

8. Montjoy C, Hadique S, Graeber G, Ghamande S, Intralobar bronchopulmonary sequestra in adults over age 50: case series and review, WV Med J, 2012;108:8-13.

9. Kim TE, KWOn JH, Kim JS, Transcatheter embolization for massive hemoptysis from an intralobar pulmonary sequestration: a case report, Clin Imaging, 2014;38:326-9.

10. Ojha V, Samui PP, Dakshit D, Role of endovascular embolization in improving the quality of life in a patient suffering from complicated intralobar pulmonary sequestration - a case report, Respir Med Case Rep, 2015;16:24-8.

11. Tashtoush B, Memarpour R, Gonzalez J, et al., Pulmonary sequestration: a 29 patient case series and review, I Clin Diagn Res, 2015;9:AC05-8.

12. Schloricke $E$, Hoffmann $M$, Kujath $P$, et al., Managemen of the therapy of pulmonary sequestration:

a retrospective multicentre study, Zentralb/ Chir, 2016;141:S50-7.

13. Huang LK, Tsai MJ, Chao HS, et al., Role of Doppler sonography in the diagnosis of pulmonary sequestration in an elderly patient: a case report, I Clin Ultrasound, 2011:39:296-300.

14. Al-Timimy QA, Al-Shamseei HF, Intralobar pulmonary sequestration in elderly woman: a rare case report with emphasis on imaging findings, Radiol Case Rep, 2016;11:144-7.

15. Zhao M, Chang B, Wei Z, et al., The role of ${ }^{18 F-F D G}$ uptake features in the differential diagnosis of solitary pulmonary lesions with PET/CT, World I Surg Oncol, 2015;13:271.

16. Rubin EM, Garcia H, Horowitz MD, Guerra JJ Jr, Fatal massive hemoptysis secondary to intralobar sequestration, Chest, 1994;106:954-5. 